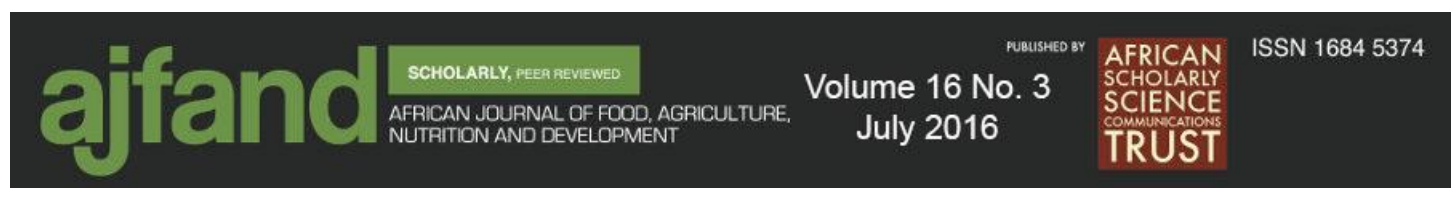

10.18697/ajfand.75.ILRI02

\title{
AFLATOXIN EXPOSURE AMONG YOUNG CHILDREN \\ IN URBAN LOW-INCOME AREAS OF NAIROBI AND ASSOCIATION WITH CHILD GROWTH
}

Kiarie GM1,2, Dominguez-Salas $P_{1,3,4}$, Kang'ethe SK2, Grace D 1and J Lindahl1,5*

*Corresponding author email: j.lindahl@cgiar.org

${ }^{1}$ International Livestock Research Institute, P.O. Box 30709-00100, Nairobi, Kenya

${ }^{2}$ School of Health Sciences, Mount Kenya University, P.O. Box 342-01000, Thika, Kenya

${ }^{3}$ Veterinary Epidemiology, Economics and Public Health Group, Royal Veterinary College, Hawkshead Lane, Hatfield, Hertfordshire A197TA, United Kingdom

${ }^{4}$ Leverhulme Centre for Integrated Research on Agriculture and Health, 36 Gordon Square, London, WC1H OPD, United Kingdom

${ }^{5}$ Department of Clinical Sciences, Swedish University of Agricultural Sciences, P.O. Box 7054, SE-750 07 Uppsala, Sweden 


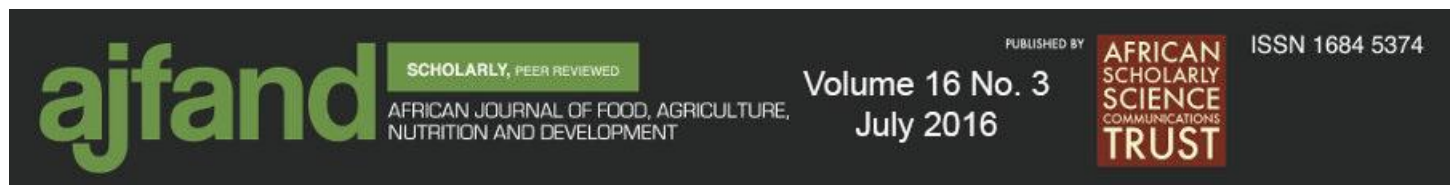

\begin{abstract}
Populations in tropical and subtropical developing countries are exposed to largely uncontrolled levels of aflatoxins through food. These countries (especially in Africa and Asia) also present a high prevalence of stunting. Studies have reported an association between aflatoxin exposure and growth impairment in children but there is not yet conclusive evidence that aflatoxins are a significant cause of stunting in children, thus further research is warranted. In this cross-sectional study, 204 low-income households were randomly selected in two low-income areas of Nairobi, Kenya. Korogocho is a higher population density area and Dagoretti a lower population density area. We asked questions about household demographics and a 24-hour dietary recall was conducted in children aged 1-3 years. Child anthropometric measurements were also conducted. Height-for-age Z-scores (HAZ), weight-for-age Z-scores (WAZ) and weight-for-height Z-scores (WHZ) were calculated for each child using World Health Organization (WHO) growth standards reference data. Samples of foods were taken from the household or from the retailer for analysis using competitive enzyme-linked immunosorbent assay (ELISA). Laboratory results for aflatoxin levels in the food samples collected were used to calculate the daily aflatoxin intake, according to the results from the dietary assessment. The study found $41 \%$ of children sampled had stunted growth. Boys were more stunted than girls $(\mathrm{p}=0.057)$ and Korogocho had more stunted children than Dagoretti $(\mathrm{p}=0.041)$. In all, $98 \%$ of food samples collected tested positive for aflatoxin and there was an average exposure to aflatoxins of $21.3 \mathrm{ng} / \mathrm{kg}$ bodyweight per day. Exposure to aflatoxin M1 (AFM1), location and sex were significantly associated with HAZ, with boys and children from Korogocho having lower HAZ, and AFM1 was negatively associated with HAZ ( $\mathrm{p}=0.047)$, indicating that AFM1 was associated with stunting. There was no association between total aflatoxins (aflatoxin B [AFB] and aflatoxin G [AFG]) and HAZ, WAZ and WHZ. The study showed a high prevalence of malnutrition, especially stunting, in two low-income urban sites, and this was most pronounced in the high-density area. The reported association between AFM1 and stunted children indicates that more research is needed on the health impacts of this aflatoxin in growing children.
\end{abstract}

Key words: stunting, aflatoxin M1, contamination, exposure, mycotoxin, ELISA, aflatoxins, mycotoxins, aflatoxin B1 


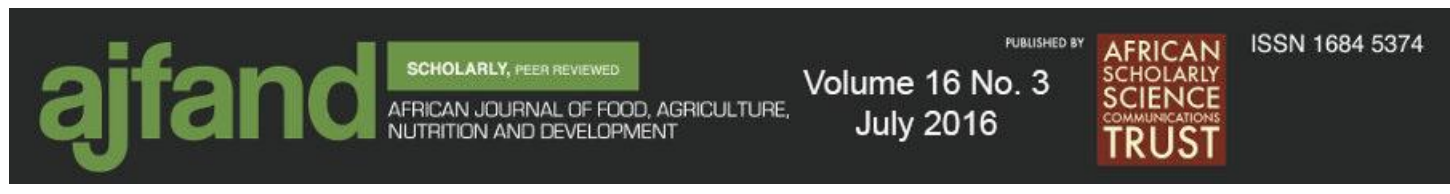

\section{INTRODUCTION}

Impaired growth is an important public health problem as it leads to long-term negative impacts on physical and psychological development. Poor nutrition brought about by food insecurity and disease has exposed African children to growth faltering, especially in places prone to famine and drought, political instability and poverty [1]. Stunting is the consequence of chronic restriction of a child's potential to grow. Once established, stunting is difficult to reverse; stunted children have been reported to be more prone to illness and stunting has also been associated with developmental and cognitive problems [2].

According to United Nations estimates, $25 \%$ of children under five years of age, or 162 million children, were stunted in 2012. Sub-Saharan Africa and South Asia have the highest prevalence (about 38\%) [3]. Kenya is no exception, and previous studies have reported $40 \%$ stunting in children between zero and 42 months of age in Korogocho and Viwandani, both low-income areas of Nairobi [4]. It has recently been shown that, even if a package of the most effective nutrition-sensitive strategies were scaled up to cover $90 \%$ of the population affected, it would reduce stunting by only $20.3 \%$ [5]. Therefore, there is need to investigate other causes of stunting, in order to design strategies to combat them. Studies have reported an association between aflatoxin exposure and growth impairment $[6,7]$ although a biological mechanism on how they might act is currently unknown, with some theories suggesting changes in intestinal integrity [8].

Aflatoxins are toxic products of Aspergillus species, particularly Aspergillus flavus and A. parasiticus. Aspergillus species are common and widespread in nature, their native habitat being the soil and decaying vegetation. They invade all types of organic substrates whenever conditions are favourable. Aflatoxins have been shown to contaminate food and feed in tropical and subtropical areas. They are produced by fungal action during production, harvest, storage and food processing. Temperatures between $24^{\circ} \mathrm{C}$ and $35^{\circ} \mathrm{C}$ and moisture content of above $7 \%$ are conditions necessary for Aspergillus species to produce aflatoxins [9]. Aflatoxins are found in a variety of foods including cereals, oil seeds, spices, tree nuts, milk, meat and dried fruits [10]. Weaning foods in Kenya are mostly composed of cereals [11] and may serve as a conduit for aflatoxin exposure. Ingestion of large doses of aflatoxin can cause acute aflatoxicosis which results in illness or death usually through liver failure. Chronic aflatoxin exposure is usually asymptomatic but may cause a range of consequences, the most well-established being liver cancer [9].

Although epidemiological data indicate association between aflatoxin exposure among children and stunting [7, 12,13], and experiments in animals show a causal link between aflatoxins and stunting [12], there is still limited evidence that aflatoxins are a significant cause of stunting in children; further research is warranted. A study conducted in Kisumu, Kenya reported an association between aflatoxin content in household food and wasting [11], but not much is known about aflatoxin and nutrition status in Kenyan resourceconstrained urban populations. 


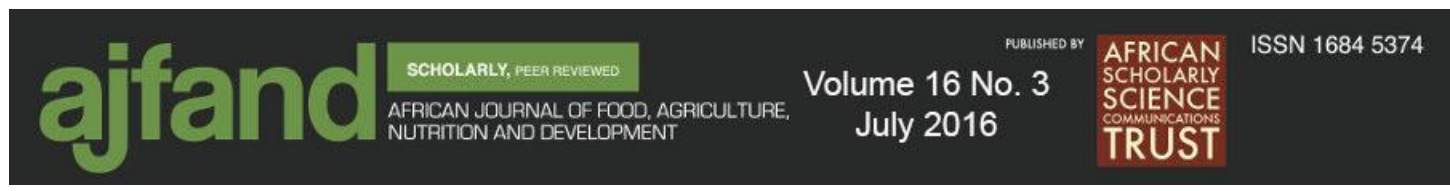

This study investigated the level of aflatoxin exposure in infants living in poor urban households in Nairobi and the potential effect of this exposure on growth.

\section{MATERIALS AND METHODS}

\section{Study sites}

The study was carried out in two informal settlements of Nairobi County, namely, Korogocho and West Dagoretti (now divided into North and South Dagoretti), between November 2013 and February 2014. They were purposively chosen for their characteristic of being poor urban areas with expected unregulated informal supply chains. Dagoretti, with a lower population density than Korogocho, also has high animal production and a wider variety of food sources. Korogocho, located in Kasarani Division, northeast of Nairobi city centre, is the fourth largest informal settlement in Kenya after Kibera, Mathare and Mukuru kwa Njenga [14]. Dagoretti lies in western Nairobi and, administratively, was one of eight divisions of Nairobi. Dagoretti division was divided into six locations: Waithaka, Kawangware, Mutuini, Kenyatta, Uthiru and Riruta [15].

\section{Sampling technique}

The study population consisted of low-income households as defined by area, type of structure (that is, formal versus informal) and monthly income. The inclusion criteria were: low monthly income, informal housing structures as well as the presence of a child between 12 and 36 months of age and a non-pregnant woman of reproductive age living in the household. Kenyan wealth index for surveys (the bottom half) references were used to generate a monthly income cut-off point where those households that reported to have below 20,000 Kenya shillings (approximately 320 United States dollars) were sampled.

Simple random selection was used, aided by computer-generated random Global Positioning System points in a map. For each point generated, the closest household to the right facing north was approached. If the household did not match the eligibility criteria, or the household did not consent to take part in the study, the next household (closest to the household on the right, facing north) was visited until a suitable household was identified and consented. If a household was eligible but empty at the time of the visit, the team returned at a different time/day for up to three times. If a parent/guardian had two children between one and three years of age, one of them was randomly selected (by tossing a coin). Similarly, if more than one pair of mother and child resided in the household, only one was randomly selected to avoid internal correlation of dietary data collected.

Once the household was identified, the enumerators asked questions about child dietary intake and conducted anthropometric measurements. When maize, groundnuts, sorghum and milk were available at the household, food samples were taken from the top, middle and bottom of the food container if the food was kept in a big container or, if food was kept in a small paper bag, shaking was done to mix thoroughly prior to sampling. If samples were not available in the household at the time of the interview, the details of the retailer where the product was usually purchased were collected and samples were then bought for analysis from the same retailer. Whenever possible, the seller was 


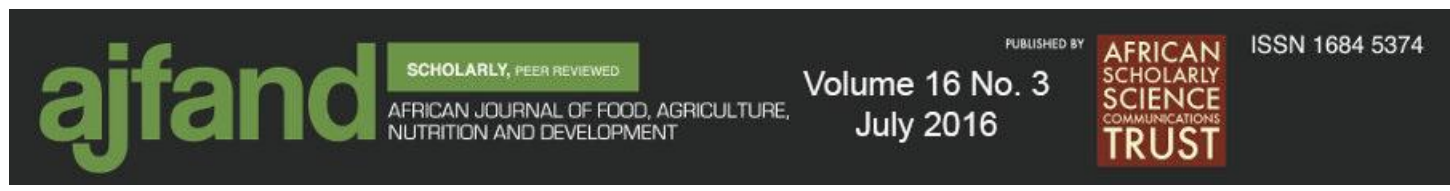

encouraged to mix the contents before sampling. Animal milk fed to children was collected in sterile tubes. The samples were stored in cooler boxes during transport to the laboratory and kept frozen at $-20^{\circ} \mathrm{C}$ until analysis. The dry samples were collected in coded paper bags and transported the same day to the laboratory where they were kept in a cold room until analysis.

\section{Data collection methods and procedures}

\section{i. Anthropometric measurements}

Weight and height were measured.

\section{a. Weight}

Weight was determined using an electronic digital scale (SECA 887) on a smooth, flat and hard surface and measured to the nearest $0.1 \mathrm{~kg}$. Two weight measurements were taken, and a third time in the cases where the two initial measurements disagreed by more than $0.2 \mathrm{~kg}$. Children were weighed nude or with diapers/light clothing with adjustment, either standing alone or being held by the care giver.

\section{b. Height}

Either height or length was measured to the nearest $0.1 \mathrm{~cm}$ using a UNICEF wooden length board for children. Height/length was measured twice, and a third time in the cases where the two initial measurements disagreed by more than $0.5 \mathrm{~cm}$. Length was measured only for children aged 12-23 months, otherwise, height was measured.

\section{ii. Dietary intake (24-hour recall)}

We used four-pass 24-hour dietary recall to estimate the amount of food consumed by the child the previous day; among them, milk, maize and sorghum were important to this study. Subjects were prompted to recall what they had fed their child the previous day and a food model was used to estimate the amount. Later, the actual weight was estimated by converting the weight of the model to the actual food item. From the dietary intakes, daily nutrition intakes (carbohydrates, proteins and fats) were calculated using global standards in Optifood.

\section{iii. Aflatoxin analysis}

Aflatoxin levels were analysed using commercial low matrix enzyme-linked immune-sorbent assay (competitive ELISA) from Helica Biosystems Inc., (1527 W Alton Ave, Santa Ana, CA 92704, United States). For maize and sorghum, total aflatoxins (AFB1, AFB2, AFG1 and AFG2) were measured in parts per billion (ppb) using total aflatoxin assay, Cat. No. 981AFL01LM-96.

For milk aflatoxin, aflatoxin M1 (AFM1) levels were measured in parts per trillion (ppt) using AFM1 (AFM1 low matrix ELISA, Cat. No. 961AFLM01M-96). All ELISA was done following the manufacturers' manuals. Analysis was done in duplicates and if results differed by more than $0.02 \mathrm{ppb}$, the analysis would be repeated. Maize and sorghum samples were categorized as 'beyond set levels' if they exceeded the current East African Community standard [16] of $10 \mathrm{ppb}$. Those that exceeded the previous Kenya Bureau of Standards regulatory limit for aflatoxin in 


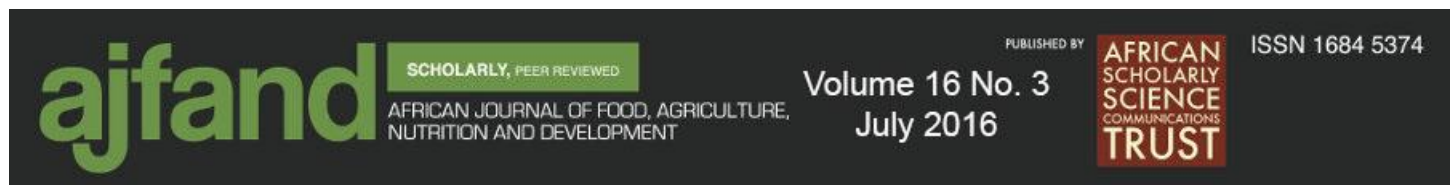

products for human consumption, 20 ppb as per 2004 [17], were also reported. The European Union (EU) set limit of $0.05 \mathrm{ppb}$ was used for milk as there is no specified standard for aflatoxin in milk in Kenya [18].

\section{Data analysis}

All data on the participants except 24-hour dietary recall (that is, data on anthropometric and social economic status) as well as the food sample details were collected using Open Data Kit (ODK) software and automatically entered into a database in Microsoft Access or Microsoft Excel on a secure server. The ODK database had built-in checks so that unrealistic values were detected upon entry. Anthropometric data were transferred into ENA/EpiInfo for quality checks to calculate child height-for-age Z-scores (HAZ), weight-for-age Z-scores (WAZ) and weight-for-height Z-scores (WHZ) using the 2006 World Health Organization (WHO) growth standards reference data. The Z-score is the measurement used in child growth to indicate by how many standard deviations a child deviates from the internationally calculated mean. Children are considered stunted if their HAZ is two or more standard deviations below the mean [19]. Other than HAZ, WAZ and WHZ are also used to indicate growth. Children with a Z-score of two or more standard deviations below the mean weight at a given age are considered underweight and if their WHZ is two standard deviations below the mean, they are considered wasted [20]. Children are considered severely affected if Z-scores are more than three standard deviations below the mean.

Laboratory results on aflatoxin levels in the food samples collected were used to calculate the daily aflatoxin intake for each child. The aflatoxin contamination data were integrated in the results from the child 24-hour dietary recall to help determine the amount of intake of the targeted foods by each child.

\section{Equations}

Exposure $(\mu g)=$ Aflatoxin level $(\mu g / k g) *$ Dietary intake $(\mathrm{g})$

Total daily exposure $=\underline{\text { Exposure from maize }+ \text { Exposure from sorghum }+ \text { Exposure from milk }}$ Body weight

Total daily exposure to AFM1 = Exposure from milk

$$
\text { Body weight }
$$

Total daily AFB/AFG exposure $=\underline{\text { Exposure from maize }+ \text { Exposure from sorghum }}$

$$
\text { Body weight }
$$




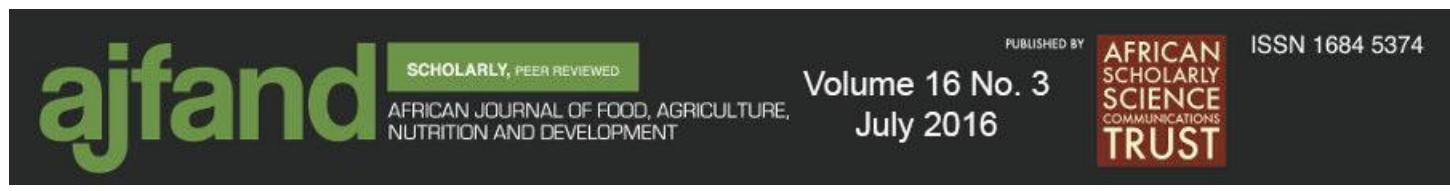

Due to the small sampling volumes and the risk that the aflatoxin levels measured were not fully representative of long-term exposure, aflatoxin levels were averaged on a village level (villages are clusters of houses built in close proximity to one another, usually demarcated by streets for administrative purposes) for all calculations except exposure per day. Averages of available samples in each of the 16 villages (parts of the informal settlements) were calculated and used instead of actual exposure in the model below. Using these measurements, the proportion of the contributions to the total exposure from milk, maize and sorghum, respectively, was calculated for each child.

To evaluate the association between aflatoxin exposure and stunting, wasting and underweight, multiple regression models were built. The mixed procedure in STATA 13.1 (Statcorp, Texas, USA) was used with restricted maximum likelihood, with village as a random effect. HAZ, WAZ and WHZ were used as the dependent variables, and AFM and total aflatoxin (AFB1, AFB2, AFG1 and AFG2) consumption $/ \mathrm{kg}$, protein $/ \mathrm{kg}$, fat $/ \mathrm{kg}$, carbohydrates $/ \mathrm{kg}$, gender, whether the child is currently breast fed, and location (Dagoretti or Korogocho) were added as independent variables. Aflatoxin exposure was forced in the model and a backward elimination was used to eliminate independent variables which were not significant or believed to be confounding (Equation 1).

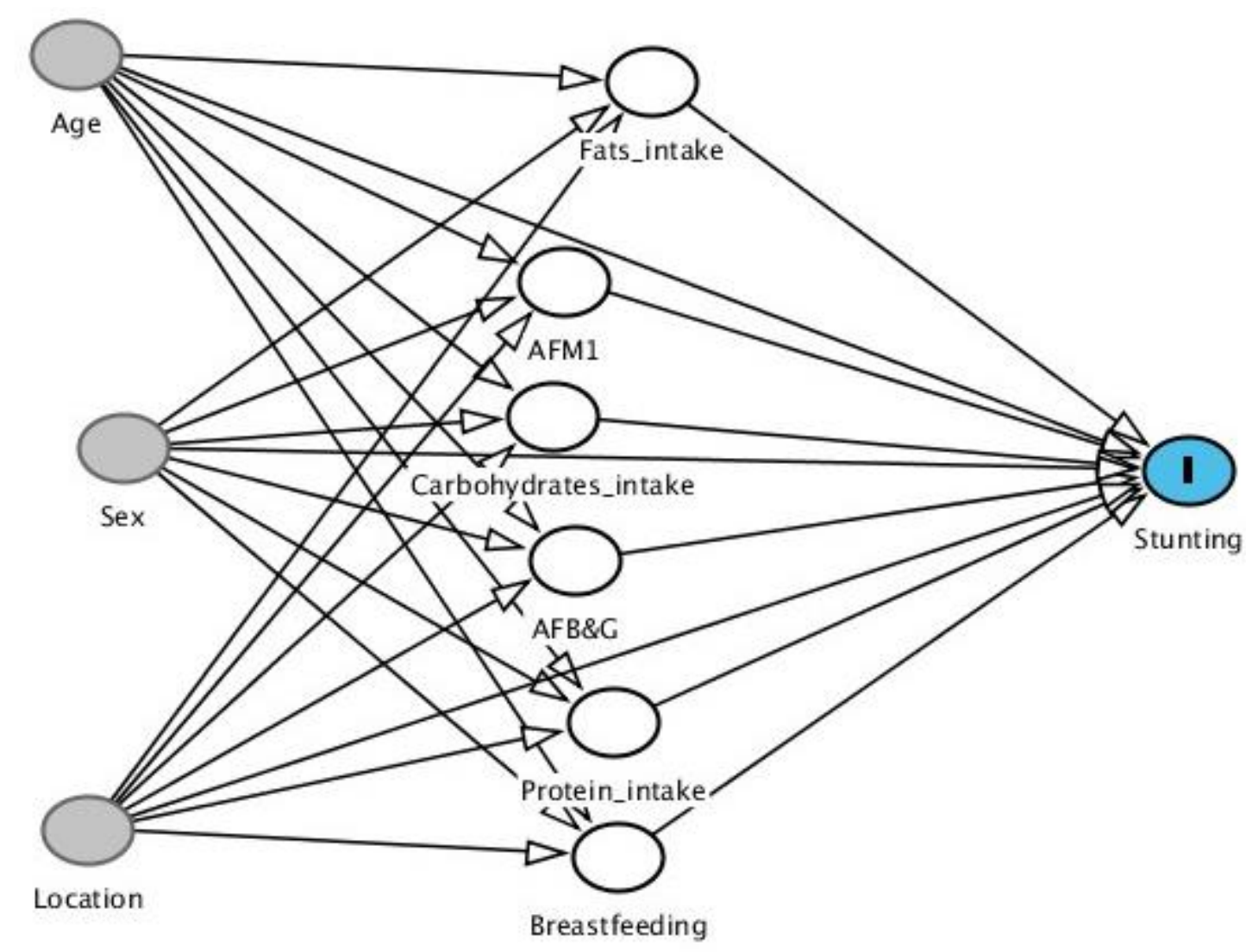

Figure 1: Conceptual framework and causal diagram for the potential effect of aflatoxin and other variables on stunting 


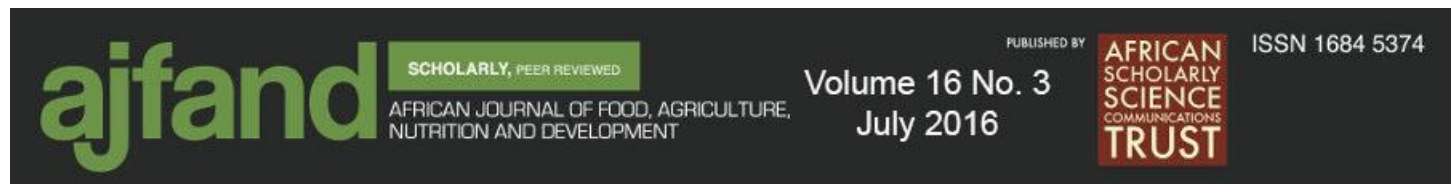

The model shown in Figure 1was used to evaluate relationships between various variables and the model used to evaluate impact on stunting is shown in Equation 1.

Equation 1:

$Y_{i}=\beta_{0}+\beta_{(A F M I)} X_{(A F M I)}+\beta_{(A F B G)} X_{(A F B G)}+$

$\beta_{(\text {carbohydrates })} X_{(\text {carbohydrates })}+\beta_{(\text {fat })} X_{(\text {fat })}+\beta_{(\text {protein })} X_{(\text {protein })}+\beta_{(\text {sex })} X_{(\text {sex })}+\beta_{(\text {age })} X_{(\text {age })}+\beta_{(\text {breastfeeding })}$

$X_{(\text {breastfeeding })}+\beta_{(\text {location })} X_{(\text {location })}+\mu_{(\text {village })}+\varepsilon_{i}$

\section{Ethical considerations}

Ethical approval was obtained from the International Livestock Research Institute (ILRI) Institutional Research Ethics Committee in Kenya (ILRI-IREC2013-14). All participants' care givers were informed about the purpose of the study and signed consent forms prior to the interview. As compensation for the foods collected at household level, all food samples were replaced by ultra-heat treated milk.

\section{RESULTS}

In total, 403 samples were collected and analysed for aflatoxin content using ELISA. These comprised 128 samples of milk, 186 samples of maize flour and 89 samples of sorghum flour. In total, it was possible to detect aflatoxins in $100 \%$ of milk, $95 \%$ of maize and $100 \%$ of sorghum samples collected. Seven $(4 \%)$ samples of maize and $1 \%$ of sorghum samples had aflatoxin concentrations higher than $20 \mathrm{ppb} ; 16 \%$ and $11 \%$ of the maize and sorghum samples, respectively, contained aflatoxins at levels that exceeded $10 \mathrm{ppb}$. Also, $81(63 \%)$ samples of milk had aflatoxin levels of more than the level of $0.05 \mathrm{ppb}$ recommended by the EU [18]. Overall, $13 \%$ of the milk samples were collected from the households while more than $70 \%$ were collected from retailers (mainly roadside vendors/kiosks), $69 \%$ of maize samples and $40 \%$ of sorghum samples were collected from the household while the rest were bought from retailers. The average aflatoxin content in maize was $6.70 \mathrm{ppb}$ in Korogocho (median $1.02 \mathrm{ppb}$, range 0-88.8 ppb) and $2.97 \mathrm{ppb}$ in Dagoretti (median $0.34 \mathrm{ppb}$, range 0-20 ppb). The average aflatoxin content of sorghum was $8.07 \mathrm{ppb}$ in Korogocho (median $1.4 \mathrm{ppb}$, range 0.1-194.4 ppb) and 2.59 ppb in Dagoretti (median $1.5 \mathrm{ppb}$, range 0.2-14.5 ppb), while the average AFM1 content in milk was $0.13 \mathrm{ppb}$ in Korogocho (median 0.074 ppb, range 0.007-2.56 ppb) and 0.09 ppb in Dagoretti (median $0.06 \mathrm{ppb}$, range 0.002-0.64 ppb) (Table 1 and Figure 2). There was an average intake of $178.54 \mathrm{~g}$ of milk, $70.64 \mathrm{~g}$ of maize and $38.85 \mathrm{~g}$ of sorghum per day for children who were identified as having consumed them during the 24-hour recall. However, including children who had not consumed these foods, the average consumption was $126.9 \mathrm{~g}$ of milk (median 66.1, range 0-904), $45.4 \mathrm{~g}$ of maize (median 34.4 range $0-406.8$ ) and $8.0 \mathrm{~g}$ of sorghum (median 0, range $0-202$ ) per day. In all, $43 \%$ of our subjects were still being breastfed at the time of assessment. 

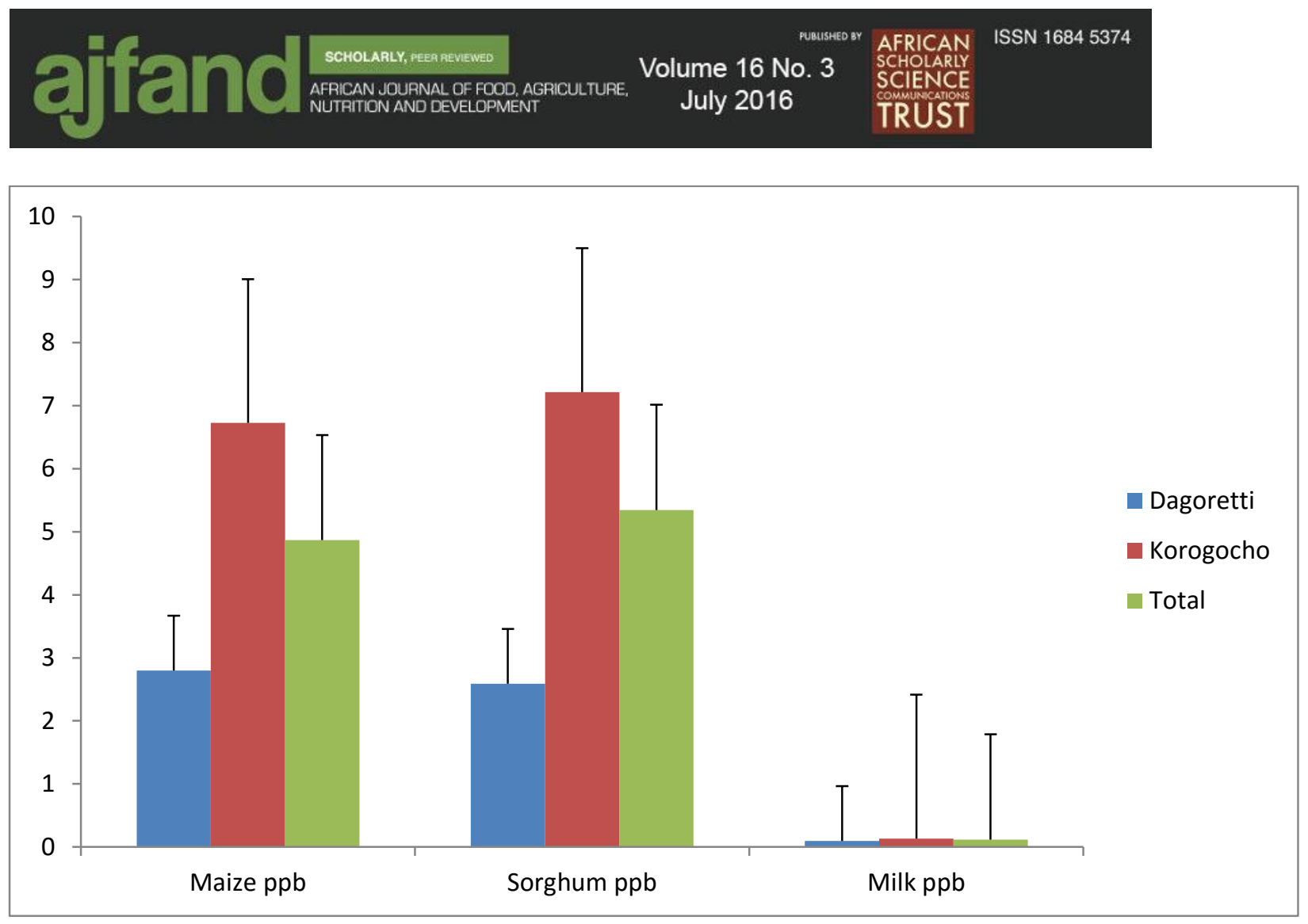

Figure 2: Average aflatoxin content (Aflatoxin B (AFB) and Aflatoxin G (AFG) in maize and sorghum and AFM1 in milk) in samples collected from Korogocho and Dagoretti. Error bars indicate the standard error

\section{Nutrition status indicators}

The study sampled 204 children between the ages of 12 and 36 months of whom 88 were females and 116 males (Table 2); they were classified into categories according to their anthropometric measurements. According to the WHZ, $4 \%$ of the subjects were wasted, $5 \%$ overweight and $91 \%$ normal (Figure 3). Korogocho had a higher proportion of wasted children than Dagoretti (7\% and 2\%, respectively) (Table 2). According to the HAZ, $41 \%$ of all the children were stunted (Figure 4), and Korogocho had a higher proportion of stunted children (49\%) than Dagoretti (34\%) (Table 2). Most children were of normal weight for their ages, and $17 \%$ of all children were underweight (Figure 5), Korogocho had more underweight (21\%) than Dagoretti (12\%) (Table 2). 

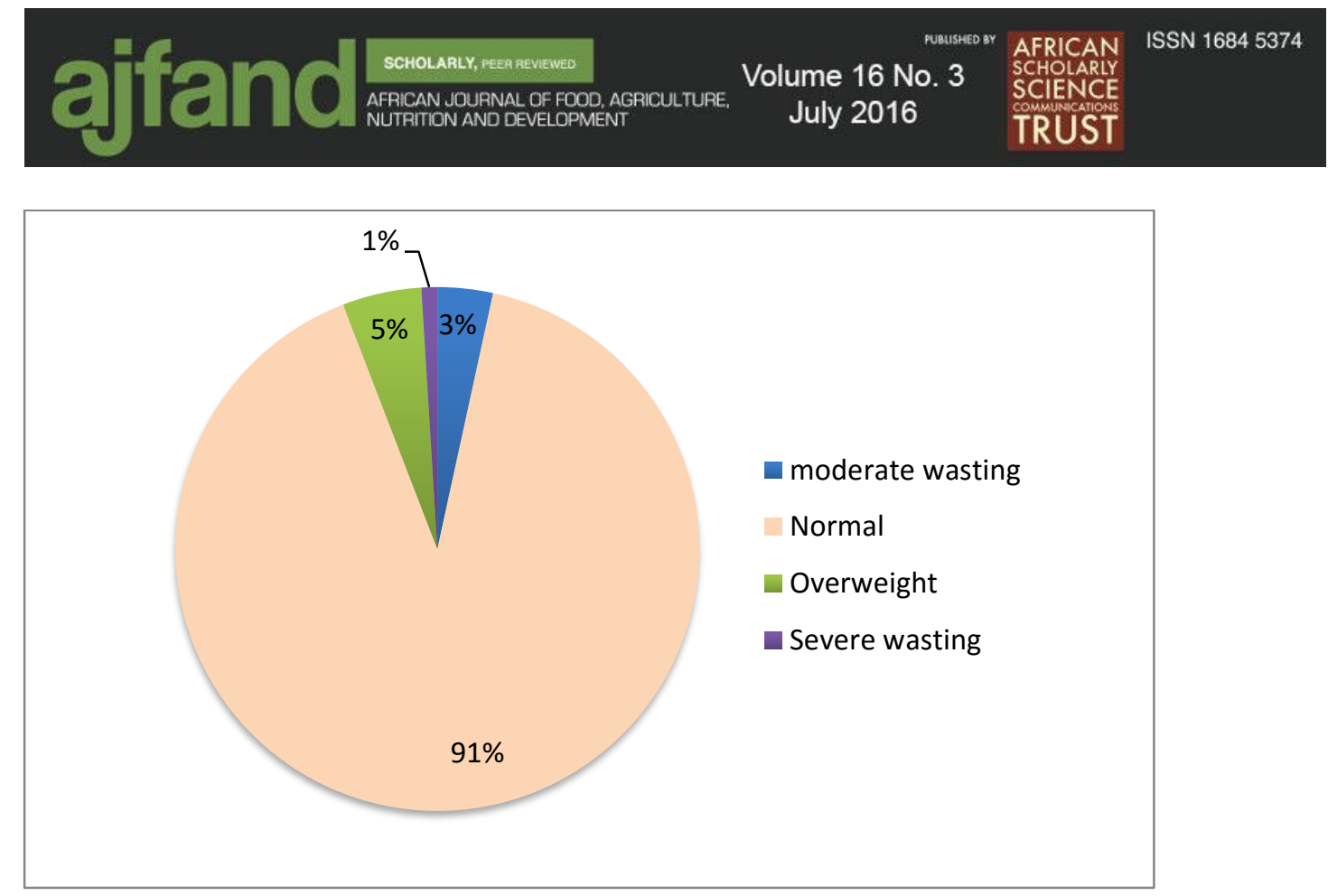

Figure 3: Distribution of children's weight-for-height Z-scores; categories were: < -3 (Severely wasted), -3 to -2 (Moderately wasted), -2 to 2 (Normal) and $>2$ (Overweight)

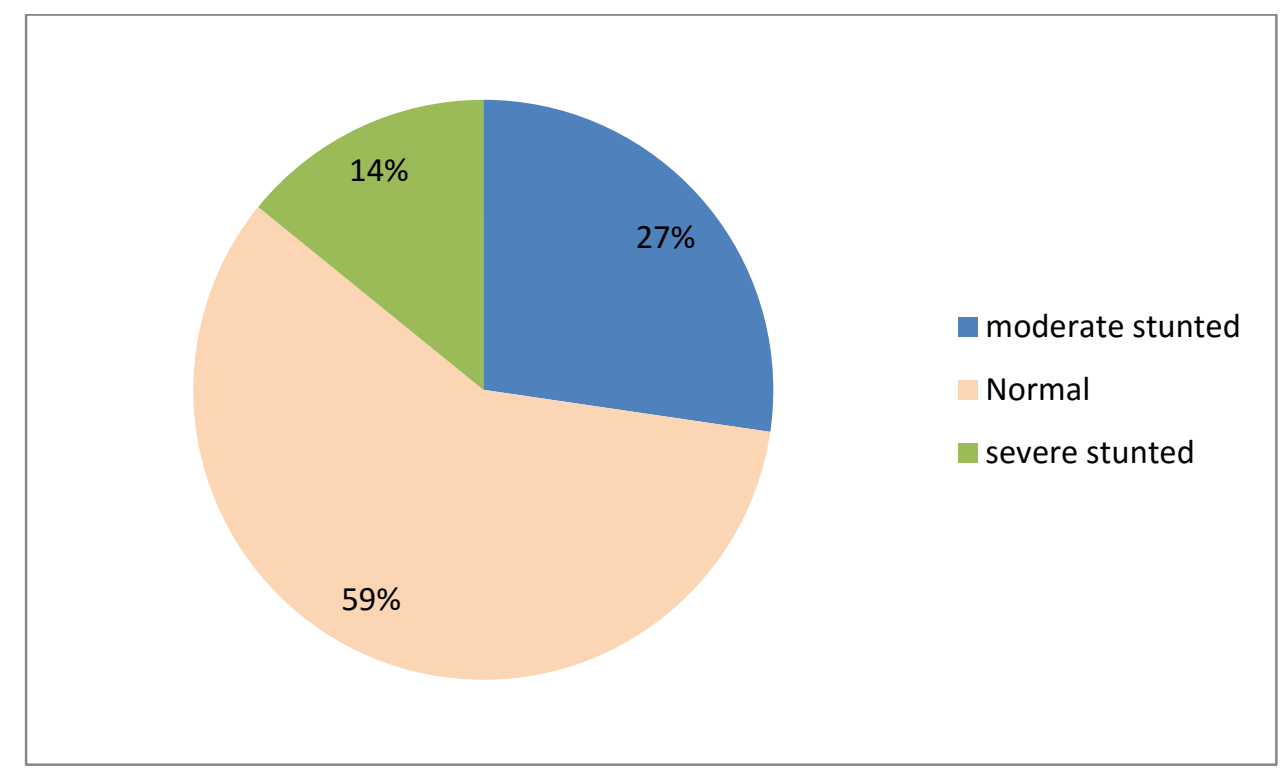

Figure 4: Distribution of children's height-for-age Z-scores, where: $<-3$ (Severely stunted), -3 to -2 (Moderately stunted) and > -2 (Normal) 

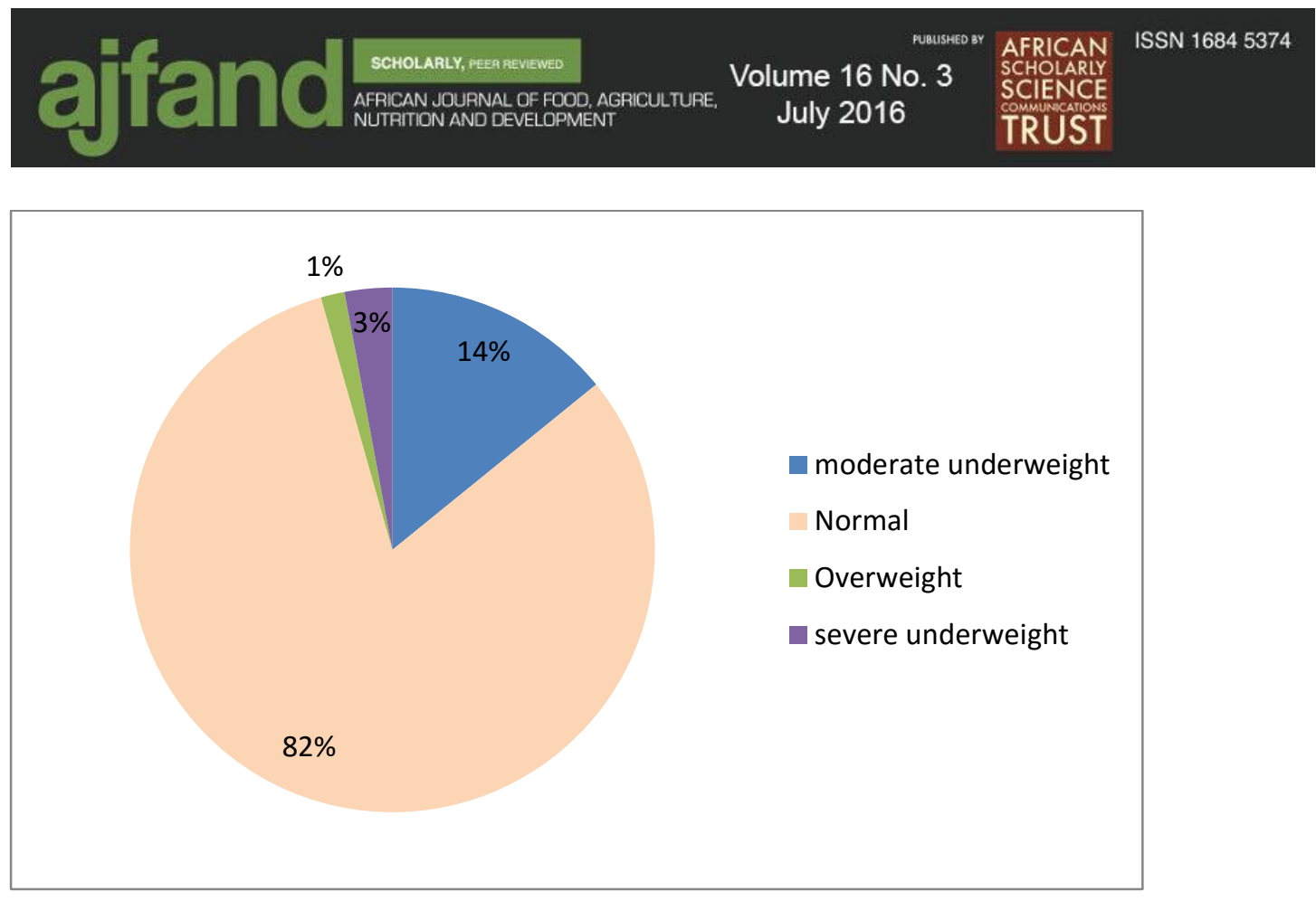

Figure 5: Distribution of children's weight-for-age $Z$-scores, where: $<-3$ (Severely underweight), -3 to -2 (Moderately underweight), -2- to 2 (Normal) and > 2 (Overweight)

\section{Daily aflatoxin exposure}

The highest average daily aflatoxin exposure was from maize ( $244.5 \mathrm{ng}$, median $8.4 \mathrm{ng}$, maximum 14,038 ng) followed by sorghum ( $38.5 \mathrm{ng}$, median $0 \mathrm{ng}$, maximum $707 \mathrm{ng}$ ), while milk (10.6 ng, median $3.7 \mathrm{ng}$, maximum $115.4 \mathrm{ng}$ ) was the least important source of exposure. Most exposure was from maize (average 59.5\%, median $82.8 \%$ ) but ranged from $0-100 \%$ in the children. Similarly, the exposure from milk also ranged between 0 and $100 \%$, (average $27.6 \%$, median $6.6 \%$ ). The exposure from sorghum was the least, on average $12.9 \%$, with median $0 \%$ in a child.

Daily aflatoxin (AFB, AFG and AFM) exposure per kilogram of bodyweight (kgbw) ranged from 0 to $197.0 \mathrm{ng} /$ day with an average of $21.3 \mathrm{ng} / \mathrm{kgbw} /$ day (median 3.6). The mean exposure in Dagoretti was $36.7 \mathrm{ng} / \mathrm{kgbw} /$ day while in Korogocho it was 13.6 ng/kgbw/day.

When factors (AFM1, AFB and AFG, protein $/ \mathrm{kg}$, fat $/ \mathrm{kg}$ and carbohydrates $/ \mathrm{kg}$ intakes, breast feeding, sex, age and location) suspected to be associated with stunting status were included in a mixed regression model, AFM1, sex and location were the factors with a significant association with HAZ (Table 3 and Figure 6). Aflatoxin M1 intake contributed negatively to HAZ; boys also had lower scores, as well as children in Korogocho. When the same model was fitted with WAZ and WHZ as the dependent variables, exposure to neither AFM1 or total other aflatoxins came out as significant (Table 4 and Table 5). 

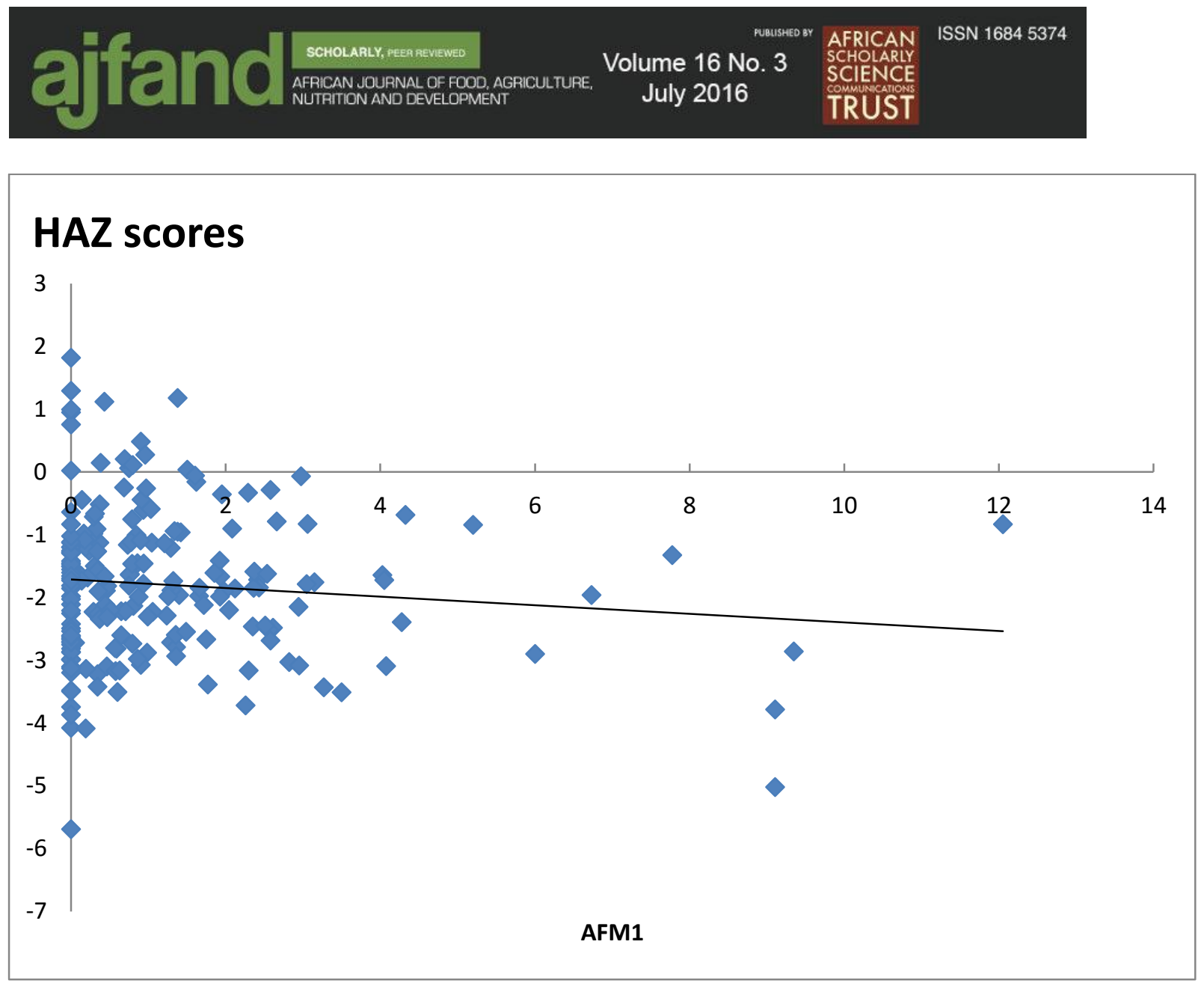

Figure 6: Correlation between $\mathrm{HAZ}$ and AFM1 exposure in $\mathrm{ng} / \mathrm{kg}$ body weight per day. HAZ= Height-for-age Z-score; AFM1= Aflatoxin M1

\section{DISCUSSION}

This study aimed to quantify aflatoxin exposure in infant diets in two low-income urban areas in Nairobi, Kenya and the potential effects on growth. The WHO conceptual framework on stunting [19] identifies breastfeeding, infections, household/family factors and inadequate complementary feeding as the major causes of childhood stunting and development. In this study, we hypothesized that nutrition status, indicated by HAZ, WAZ or WHZ, was influenced by both quality and quantity of food consumed but also by aflatoxin contamination in the diet.

In this study, $4 \%$ of children sampled were wasted, $41 \%$ stunted and $17 \%$ underweight. This is higher than the levels reported nationally in 2014 (4\% wasted, 26\% stunted and $11 \%$ underweight). However, the households in this sample were randomly selected from the population of poor households in the urban areas and the data are consistent with data from the lowest wealth strata of the same study which reported $7.3 \%$ wasted, $36 \%$ stunted and $19.5 \%$ underweight [21].

The percentage of milk samples analysed that had detectable levels of AFM1 in this study $(100 \%)$ is comparable with other studies in marketed milk in Portugal [22] and Greece 


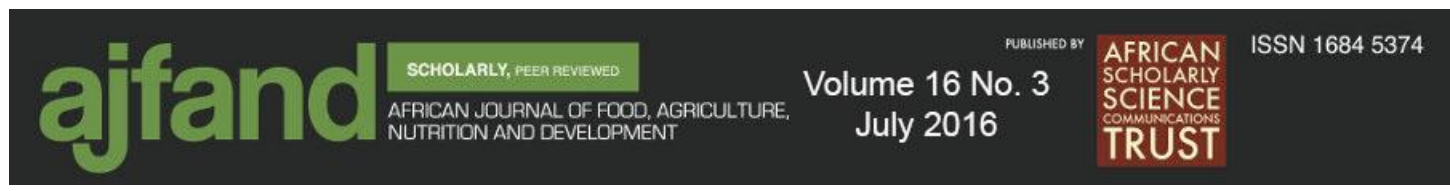

[23] more than a decade ago. A more recent study in urban centres in Kenya [24] found that $72 \%$ of milk from smallholder farmers, $84 \%$ of samples from medium- and largescale farmers and $99 \%$ of samples of marketed pasteurized milk tested positive for AFM1 and $20 \%, 35 \%$ and $31 \%$ of positive milk from smallholder farmers, medium/large-scale farmers and market outlets, respectively, exceeded the level of $0.05 \mathrm{ppb}$ [24]. The current study had more samples (63\%) with AFM1 content higher than $0.05 \mathrm{ppb}$ (the EU set limit). This might be because the previous study collected samples from a larger geographical area as compared to this study, which only had samples from two deprived districts of Nairobi. The $63 \%$ of milk samples with AFM1 levels above 0.05 ppb reported in this study is, however, lower than was reported in India where $99 \%$ of raw milk, milkbased cereal weaning formula and infant formula analysed had concentrations of AFM1 above $0.05 \mathrm{ppb}$ [25]. It is also lower than proportions reported by a recent study in Ethiopia where $100 \%$ of raw milk samples contained aflatoxins and $82 \%$ contained AFM1 at levels that were above $0.05 \mathrm{ppb}$ [26].

Only $4 \%$ of maize samples had aflatoxin concentrations of more than $20 \mathrm{ppb}$ (AFB and AFG), lower than previous reports from Kenya [27, 28], where 55\% of samples had more than $20 \mathrm{ppb}$ of aflatoxin. However, those results were from studies done in Eastern Province after the aflatoxicosis outbreak of 2004 where samples levels of AFB1 above $100 \mathrm{ppb}$ were recorded. The highest concentration recorded in this study was $88.85 \mathrm{ppb}$. The results from our study are comparable to many other studies in Africa and elsewhere. A study in Tanzania reported concentrations of up to $158 \mathrm{ppb}$ in home-grown maize [29]. A Pakistan study reported $80 \%, 85 \%$ and $90 \%$ of aflatoxin contamination of maize in urban, semi-urban and rural areas, respectively [30]. In a study in India, 100\% of maize samples analysed were contaminated with aflatoxin, with a mean level of $88 \mathrm{ppb}$ [31]. After the 2004 outbreak, the Kenya regulation for total aflatoxin permitted was changed to $10 \mathrm{ppb}$. However, the legal standards may not have much impact on the poor urban population or rural inhabitants as most maize is never inspected or tested regardless of the regulations.

Aflatoxin-positive results were found in $100 \%$ of the sorghum samples, which is much higher than 15\% reported in Mozambique from samples of sorghum used in preparation of opaque beer [32]. In this study, sorghum produced the sample with the highest concentration of aflatoxin (194 ppb) and had the highest mean aflatoxin content (5.34 $\mathrm{ppb}$ ). This might be the result of prolonged poor storage of sorghum flour, either in the households or in the outlets, because only a small amount of sorghum flour is required to prepare porridge.

On average, food samples collected in Korogocho had higher aflatoxin content than those from Dagoretti. This might be explained by the difference in average monthly income where Korogocho residents had significantly lower monthly income ranges than their Dagoretti counterparts. This is in agreement with results from a study in Eastern Province of Kenya which reported that higher aflatoxin exposure levels were associated with poverty [33].

The average exposure to aflatoxin from milk (AFM1) was $10.6 \mathrm{ng} / \mathrm{g}$, from maize, 244.5 $\mathrm{ng} / \mathrm{g}$ and from sorghum, $38.5 \mathrm{ng} / \mathrm{g}$ (AFB and AFG). Most exposure to aflatoxin $(50.7 \%)$ 


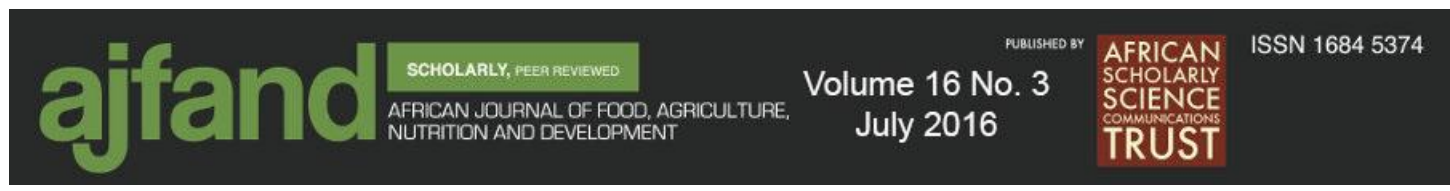

was the result of maize consumption. Maize is the main staple food for the majority of Kenyans, accounting for $36 \%$ of their daily caloric intake in this sample [34]. As shown by Muriuki and Simboe [35] who reported an average of $20 \mathrm{ppb}$ aflatoxin content in maize, and assuming an average daily maize consumption of $400 \mathrm{~g}$ per person, an adult Kenyan $(60 \mathrm{~kg})$ would be exposed to $133 \mathrm{ng} / \mathrm{kgbw} / \mathrm{day}$. In this study, it was shown that children in Korogocho and Dagoretti were exposed to an average dietary aflatoxin exposure of $27.14 \mathrm{ng} / \mathrm{kgbw} / \mathrm{day}$.

A study conducted in low-income areas in Nairobi reported that complementary foods (either liquid or solid) were introduced to infants before six months of age in $99 \%$ of cases, with liquids being introduced on average within the first month while solids were introduced by the age of three-and-a-half months. The main reason for early introduction to complementary food was that the mother had little or no milk [36]. In the current study, children aged between one and three years from low-income areas of Nairobi were sampled, so it was assumed that at this age and based on the usually early age at which complementary feeding is introduced, breast milk would constitute a small fraction of the subjects' diet and breast milk was not collected for analysis for AFM1. In all, 43\% of our subjects were still being breastfed at the time of assessment.

The difference between AFB1 and AFM1 as regards their potential to cause stunting is not clear. As a cause of hepatocellular carcinoma in male rats, AFM1 has been shown to have $2-10 \%$ of potency of the AFB1 [37]. Currently, no studies have been done on AFM1 from animal's milk as a risk factor for growth impairment, but AFM1 from mother's breast milk has been shown to correlate negatively with child nutrition status. A study in Iran reported significant lower scores in HAZ and WAZ of infants born to AFM1positive mothers [38]. Another study in the same country also reported significant association between AFM1 in maternal breast milk and height at birth of infants [39].

Aflatoxin M1, location and sex had significant correlation with HAZ in this study, whereas no association with the total of AFB and AFG could be seen. The reported correlation between sex and HAZ was in agreement with the national report [21] and epidemiological studies on neonatology depicting both morbidity and mortality to be consistently higher in males than females in early life [40], although the explanation for this trend is not yet known. Korogocho has a higher number of poor families than Dagoretti and, although the inclusion criterion was to represent the urban poor in both areas, it can be argued that Korogocho is relatively poorer and this may explain why it had a significantly higher number of stunted children than Dagoretti. Although AFM1 has been classified as a less active carcinogen than AFB1, the same cannot be assumed with regards to its potential to cause stunting since the pathways to health outcomes may differ. This study cannot be compared directly to the Benin and Togo study [13] due to their different strategies employed to assess exposure, but if we consider calculations by Shephard [41] when he converted AFB1 albumin used in the Benin and Togo study to daily aflatoxin exposure in $\mathrm{ng} / \mathrm{kg} / \mathrm{day}$, the average exposure to AFB1 in this study was very low, almost ten times lower than was found in stunted children in West Africa, which could explain why it was not a risk factor for stunting here. 
A study on swine reported that high protein dietary intake allows them to tolerate greater aflatoxin exposure [42]. Protein intake was not significantly associated with stunting in this study. This might be due to the fact that protein intake was moderate in this sample and more research would be needed to evaluate this in humans in order to understand the potential interactions here. We have not been able to find previous reports of a negative association between protein intake and WHZ and WAZ, as was unexpectedly found in this study. Children that were still breastfeeding also had lower WAZ; this might be as a result of not getting enough weaning food as their mothers might overestimate the nutritional value of the breast milk their infants get. It has been shown that prolonged breastfeeding beyond six months without introduction to weaning foods leads to malnutrition. Daily calorie intake in severely and moderately underweight and severely wasted children on average did not meet the required 1000 calories per day intake for two-year-olds, and there is a need for more in-depth studies regarding how intake of calories, proteins and toxins affects children in low-income areas. Previous studies [43, 44] have identified seasonal changes as an important factor in determining exposure to aflatoxins. It would therefore be important to carry out follow-up studies in these sites. This study was limited by the fact that only 24 -hour recall data were used and no repeated sampling of aflatoxins was possible. There are major assumptions underlying these results in the sense that it is assumed that (a) the recall is representative of long-term consumption and (b) that aflatoxin levels averaged in the village are representative of long-term exposure. The result of this small study, however, indicates the need to conduct further larger studies on the topic to better understand the associations and the causality.

\section{CONCLUSION}

This study has demonstrated the degree of exposure to aflatoxins of children in Nairobi's poor urban settings. Foods with relatively low aflatoxin content contribute cumulatively to high daily aflatoxin intake due to their high consumption frequency, more so in children whose weaning food cereals are prone to infection with Aspergillus species. Although exposure from milk (AFM1) is less than AFB1 from other foods, it should not be ignored since the relative importance of AFM1 in stunting is unknown and because milk products are an important part of the diet of infants and young children, who are more susceptible to aflatoxins. It is reasonable to envisage that cereals with high concentrations of aflatoxin, and therefore not suitable for human consumption, may end up being fed to cattle and enter the human food chain through milk products. Although the aflatoxin concentrations in milk are much lower than those in cattle feed, enough may be transferred to milk to contribute to concerning aflatoxin exposure levels in vulnerable populations.

Populations in these areas need to be carefully sensitized on the health effects of aflatoxin and how to avoid high exposure, such as substituting maize consumption with rice, coupled with education on balanced nutrition to help mitigate malnutrition. 


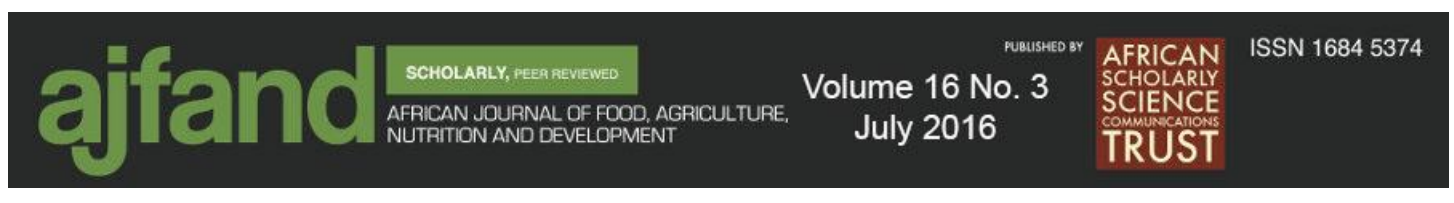

\section{ACKNOWLEDGEMENTS}

The aflatoxin study was a part of the FoodAfrica Programme which is mainly financed by the Ministry for Foreign Affairs of Finland Contract No. 29891501 (FoodAfrica), nested into a nutrition project funded by the CGIAR Research Program on Agriculture for Nutrition and Health, the Leverhulme Centre for Integrated Research on Agriculture and Health and the Urban Zoonoses project (Medical Research Council, Natural Environment Research Council, Economic and Social Research Council, Biotechnology and Biosciences Research Council through the Environmental \& Social Ecology of Human Infectious Diseases Initiative [ESEI], Grant Reference: G1100783/1).

We thank all the participants for their contributions to this research, Irene Kagera for assisting in laboratory analysis, Douglas Angogo, Judith Mwangangi and Emma Osoro who assisted in field work and Pablo Alarcon who helped in designing the project. Thanks to Ian Dohoo for advice on statistical models. 


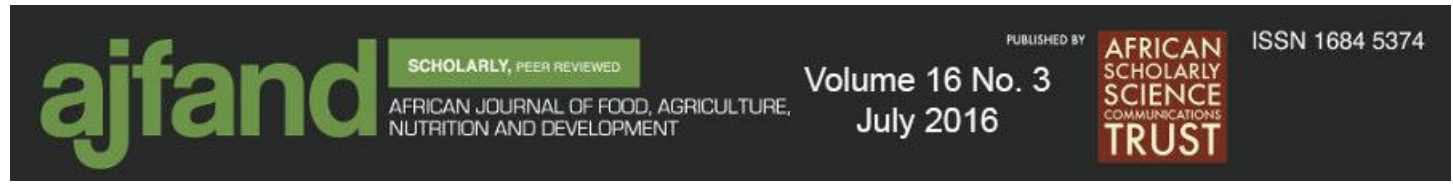

Table 1: Aflatoxin levels (ppb) in foods collected from two low-income areas in Nairobi, Kenya

\begin{tabular}{lcccccr}
\hline Food sample & \multicolumn{3}{c}{ Korogocho } & \multicolumn{3}{c}{ Dagoretti } \\
& \multicolumn{1}{c}{ N } & Mean & Range & N & Mean & Range \\
& 76 & 0.132 & $0.007-2.56$ & 52 & 0.093 & $0.002-0.64$ \\
\hline Milk (AFM1) & 99 & 6.7 & $0.0-88.83$ & 87 & 2.97 & $0-20$ \\
Maize (AFG+AFB) & 53 & 8.07 & $0.1-194.41$ & 36 & 2.59 & $0.2-14.47$ \\
Sorghum (AFG+AFB) & & & & & &
\end{tabular}

AFM1: aflatoxin M1; AFG: aflatoxin G; AFB: aflatoxin B 


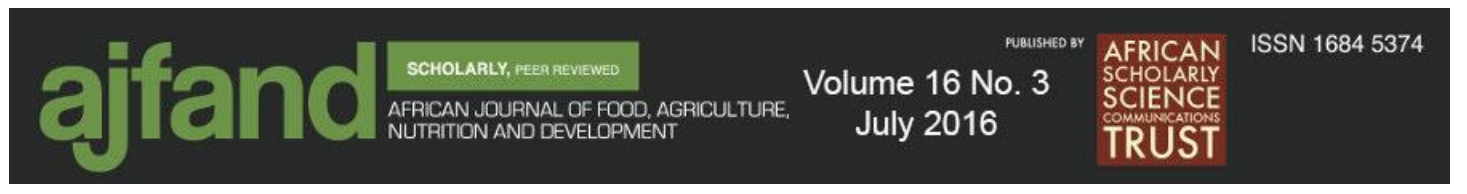

Table 2: Number of children classified according to anthropometric measurements

\begin{tabular}{|c|c|c|c|c|}
\hline & & Dagoretti & Korogocho & Total (\%) \\
\hline \multirow[t]{2}{*}{ Sex } & Male & 54 & 62 & $116(57 \%)$ \\
\hline & Female & 46 & 42 & $88(43 \%)$ \\
\hline \multirow[t]{4}{*}{ Weight-for-height Z-scores* } & Severe wasting & 1 & 1 & $2(1 \%)$ \\
\hline & Moderate wasting & 1 & 6 & $7(3 \%)$ \\
\hline & Normal & 91 & 94 & $185(91 \%)$ \\
\hline & Overweight & 7 & 3 & $10(5 \%)$ \\
\hline \multirow[t]{3}{*}{ Height-for-age Z-scores* } & Severe stunting & 11 & 17 & $28(14 \%)$ \\
\hline & Moderate stunting & 23 & 33 & $56(27 \%)$ \\
\hline & Normal & 66 & 54 & $120(59 \%)$ \\
\hline \multirow[t]{5}{*}{ Weight-for-age Z-scores* } & Severe underweight & 2 & 4 & $6(3 \%)$ \\
\hline & Moderate & 10 & 18 & $28(14 \%)$ \\
\hline & underweight & & & \\
\hline & Normal & 85 & 82 & $167(82 \%)$ \\
\hline & Overweight & 3 & 0 & $3(1 \%)$ \\
\hline
\end{tabular}

*The World Health Organization Z-score cut-off point of $<-2$ standard deviations was used to classify low height-for-age, low weight-for-height and low weight-for-age as moderate, $<-3$ standard deviations as severe under-nutrition, while $>+3$ standard deviations weight-for-height and weight-for-age was classified as overweight. 


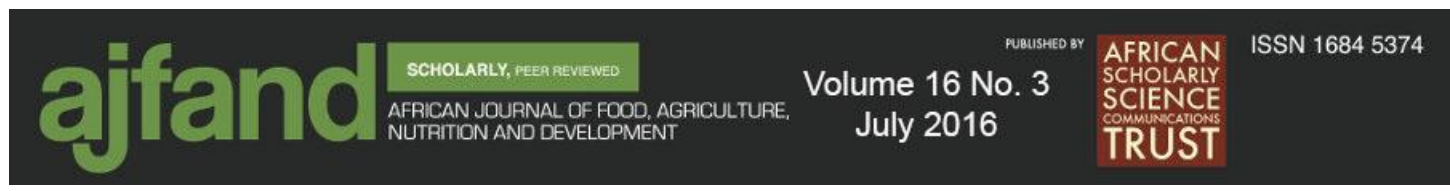

Table 3: Results of a model for height-for-age Z-scores in Dagoretti and Korogocho low-income areas in Nairobi

\begin{tabular}{lllll}
\hline & Estimate $(\beta)$ & $\begin{array}{l}\text { Standard } \\
\text { error }\end{array}$ & $\begin{array}{l}95 \% \text { confidence } \\
\text { interval }\end{array}$ & P value \\
\hline AFM1 (ng/kg/day) & -0.090 & 0.045 & $-0.178--0.001$ & 0.047 \\
AFB+AFG (ng/kg/day) & 0.003 & 0.002 & $-0.002-0.008$ & 0.216 \\
Male & -0.337 & 0.160 & $-0.652--0.023$ & 0.036 \\
Age (months) & -0.020 & 0.012 & $-0.042-0.003$ & 0.094 \\
Korogocho & -0.471 & 0.190 & $-0.843--0.099$ & 0.013 \\
Constant & -0.868 & 0.328 & & \\
\hline
\end{tabular}

AFM1: aflatoxin M1; AFB: aflatoxin B; AFG: aflatoxin G

Table 4: Results of a model for weight-for-age $Z$-scores in Dagoretti and Korogocho low-income areas in Nairobi

\begin{tabular}{lllll}
\hline & Estimate $(\beta)$ & $\begin{array}{l}\text { Standard } \\
\text { error }\end{array}$ & $\begin{array}{l}95 \% \text { confidence } \\
\text { interval }\end{array}$ & P value \\
\hline AFM1 (ng/kg/day) & -0.053 & 0.052 & $-0.155-0.048$ & 0.304 \\
AFB+AFG (ng/kg/day) & 0.0003 & 0.003 & $-0.005-0.005$ & 0.913 \\
Breast feeding & -0.426 & 0.216 & $-0.848--0.003$ & 0.048 \\
Protein intake (g/kg) & -0.150 & 0.060 & $0.267--0.033$ & 0.012 \\
Age (months) & -0.023 & 0.016 & $-0.054-0.008$ & 0.139 \\
Korogocho & -0.549 & 0.169 & $-0.881--0.217$ & 0.001 \\
Constant & 0.401 & 0.490 & & \\
\hline
\end{tabular}

AFM1: aflatoxin M1; AFB: aflatoxin B; AFG: aflatoxin G 


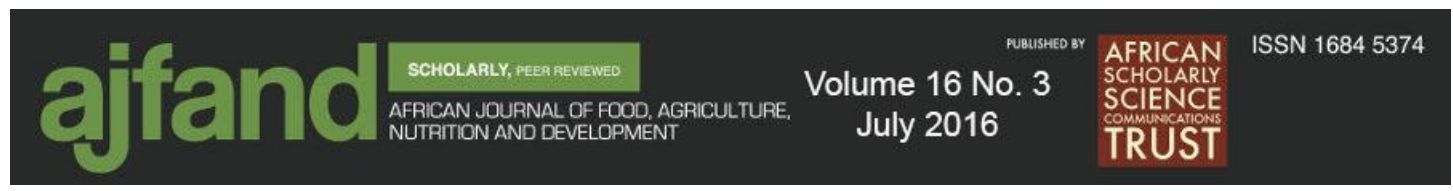

Table 5: Results of a model for weight-for-height Z-scores in Dagoretti and Korogocho low-income areas in Nairobi

\begin{tabular}{lllll}
\hline & Estimate $(\beta)$ & $\begin{array}{l}\text { Standard } \\
\text { error }\end{array}$ & $\begin{array}{l}\text { 95\% confidence } \\
\text { interval }\end{array}$ & P value \\
\hline AFM1 (ng/kg/day) & 0.020 & 0.055 & $-0.087-0.127$ & 0.718 \\
AFB+AFG (ng/kg/day) & -0.002 & 0.003 & $-0.007-0.004$ & 0.565 \\
Protein intake (g/kg) & -0.190 & 0.064 & $-0.316--0.064$ & 0.003 \\
Age (months) & 0.017 & 0.013 & $-0.008-0.043$ & 0.18 \\
Korogocho & -0.348 & 0.183 & $-0.706-0.01$ & 0.057 \\
Constant & 0.123 & 0.370 & &
\end{tabular}

AFM1: aflatoxin M1; AFB: aflatoxin B; AFG: aflatoxin G 


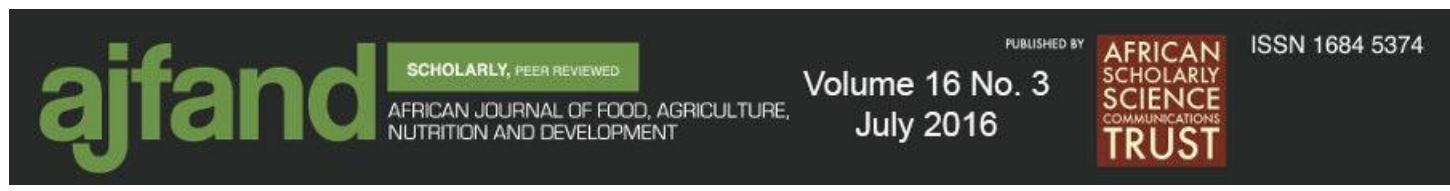

\section{REFERENCES}

1. Lombard MJ Mycotoxin Exposure and Infant and Young Child Growth in Africa: What Do We Know? Ann. Nutr. Metab. 2014; 64(2): 42-52.

2. Ricci KA, Girosi F, Tarr PI, Lim Y-W, Mason C, Miller M, Hughes J, Von Seidlein L, Agosti JM and RL Guerrant Reducing Stunting Among Children: The Potential Contribution of Diagnostics. Nature 2006; 444: 29-38.

3. UNICEF/WHO/The World Bank Joint Child Malnutrition Estimates - Levels and Trends. World Health Organization, Geneva, 2012.

4. Abuya BA, Onsomu EO, Kimani JK and D Moore Influence of Maternal Education on Child Immunization and Stunting in Kenya. Matern. Child Health J. 2011; 15(8): 1389-1399.

5. Bhutta ZA, Das JK, Rizvi A, Gaffey MF, Walker N, Horton S, Webb P, Lartey $A$ and RE Black Evidence-based Interventions for Improvement of Maternal and Child Nutrition: What Can Be Done and at What Cost? Lancet 2013; 382(9890): 452-477.

6. Turner PC, Moore SE, Hall AJ, Prentice AM and CP Wild Modification of Immune Function Through Exposure to Dietary Aflatoxin in Gambian Children. Environ. Health Perspect. 2003; 111(2): 217-220.

7. Gong Y Determinants of Aflatoxin Exposure in Young Children from Benin and Togo, West Africa: The Critical Role of Weaning. Int. J. Epidemiol. 2003; 32(4): $556-562$.

8. Gong Y, Turner PC, Hall AJ and CP Wild Aflatoxin Exposure and Impaired Child Growth in West Africa: An Unexplored International Public Health Burden? In: Leslie JF, Bandyopadhyay R and A Visconti (Eds). Mycotoxins Detection Methods, Management, Public Health and Agricultural Trade. Oxford, UK: CABI Publishing, 2008: 53-65.

9. Williams JH, Phillips TD, Jolly PE, Stiles JK, Jolly CM and D Aggarwal Human Aflatoxicosis in Developing Countries: A Review of Toxicology, Exposure, Potential Health Consequences, and Interventions. Am. J. Clin. Nutr. 2004; 80(5): 1106-1122.

10. Strosnider H, Azziz-Baumgartner E, Banziger M, Bhat R V., Breiman R, Brune M-N, DeCock K, Dilley A, Groopman J, Hell K, Henry SH, Jeffers D, Jolly C, Jolly P, Kibata GN, Lewis L, Liu X, Luber G, McCoy L, Mensah P, Miraglia M, Misore A, Njapau H, Ong C-N, Onsongo MTK, Page SW, Park D, Patel M, Phillips T, Pineiro M, Pronczuk J, Rogers HS, Rubin C, Sabino M, Schaafsma A, Shephard G, Stroka J, Wild C, Williams JT, and D Wilson Workgroup Report: Public Health Strategies for Reducing Aflatoxin Exposure in Developing Countries. Environ. Health Perspect. 2006; 114(12): 1898-1903. 


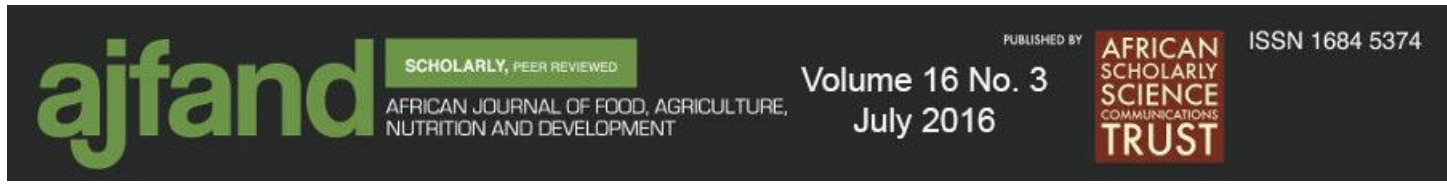

11. Okoth SA and M Ohingo Dietary Aflatoxin Exposure and Impaired Growth in Young Children from Kisumu District, Kenya: Cross Sectional Study. Afr. J. Health Sci. 2004; 11(1-2): 43-54.

12. Hall A and CP Wild Epidemiology of Aflatoxin-related Disease. In: Eaton DL and J Groopman (Eds). The Toxicology of Aflatoxins: Human Health, Veterinary and Agricultural Significance. San Diego, California: Academic Press, 1993: 233-258.

13. Gong YY Dietary Aflatoxin Exposure and Impaired Growth in Young Children from Benin and Togo: Cross Sectional Study. Br. Med. J. 2002; 325(7354): 2021.

14. Anon Korogocho: The Land and the People [Internet]. Available from: www.begakwabega.com/articolo2-eng.htm. Accessed on 12/5/2014.

15. Open Kenya/Transparent Africa Dagoretti Population [Internet]. Available from: https://www.opendata.go.ke/Population/Dagoretti-population/yvsv-j3da. Accessed on 12/5/14.

16. EAC. East Africa Standards: Maize Grains - Specification [Internet]. 2011. Available from: https://law.resource.org/pub/eac/ibr/eas.2.2011.html. Accessed on $8 / 6 / 2015$.

17. Kenya Bureau of Standards Dry-milled Maize Products. Kenyan Standard No 05158. Kenya Bureau of Standards, Nairobi, 1998.

18. The Commission of the European Communities Commission Regulation (EC) No. 2174/2003 of 12 December 2003 Amending Regulation (EC) No 466/2001 As Regards Aflatoxins. Off. J. Eur. Union 2003; 19(17): 3-5.

19. Stewart CP, Iannotti L, Dewey KG, Michaelsen KF and AW Onyango Contextualising Complementary Feeding in a Broader Framework for Stunting Prevention. Matern. Child Nutr. 2013; 9: 27-45.

20. WHO. Training Course on Child Growth Assessment: WHO Child Growth Standards. WHO, Geneva, 2008.

21. KNBS/MoH/NACC/KEMRI/NCPD/DHS Program Kenya Demographic and Health Survey 2014. Government of Kenya, Nairobi, 2015.

22. Martins ML and HM Martins Aflatoxin M1 in Raw and Ultra High Temperature-treated Milk Commercialized in Portugal. Food Addit. Contam. 2000; 17(10): 871-874.

23. Roussi V, Govaris A, Varagouli A and NA Botsoglou Occurrence of Aflatoxin M 1 in Raw and Market Milk Commercialized in Greece. Food Addit. Contam. 2002; 19(9): 863-868. 


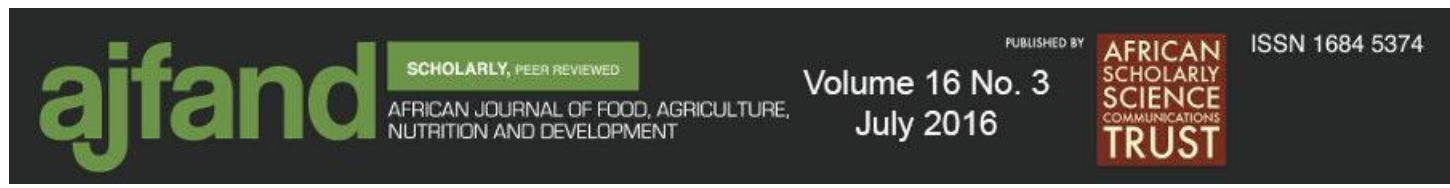

24. Kang'ethe EK and KA Lang'a Aflatoxin B1 and M1 Contamination of Animal Feeds and Milk from Urban Centers in Kenya. Afr. Health Sci. 2009; 9(4): 218226.

25. Rastogi S, Dwivedi PD, Khanna SK and M Das Detection of Aflatoxin M1 Contamination in Milk and Infant Milk Products from Indian Markets by ELISA. Food Control 2004; 15(4): 287-290.

26. Gizachew D, Szonyi B, Tegegne A, Hanson J and D Grace Aflatoxin Contamination of Milk and Dairy Feeds in the Greater Addis Ababa Milk Shed, Ethiopia. Food Control 2016; 59: 773-779.

27. Centers for Disease Control and Prevention Outbreak of Aflatoxin Poisoning - Eastern and Central Provinces, Kenya, January-July 2004. MMWR Morb. Mortal. Wkly. Rep. 2004; 53: 790-793.

28. Lewis L, Onsongo M, Njapau H, Schurz-Rogers H, Luber G, Kieszak S, Nyamongo J, Backer L, Dahiye AM, Misore A, DeCock $\mathrm{K}$ and $\mathrm{C}$ Rubin Aflatoxin Contamination of Commercial Maize Products during an Outbreak of Acute Aflatoxicosis in Eastern and Central Kenya. Environ. Health Perspect. 2005; 113(12): 1763-1767.

29. Kimanya ME, De Meulenaer B, Tiisekwa B, Ndomondo-Sigonda M, Devlieghere F, Van Camp J and P Kolsteren Co-occurrence of Fumonisins with Aflatoxins in Home-stored Maize for Human Consumption in Rural Villages of Tanzania. Food Addit. Contam. Part A 2008; 25(11): 1353-1364.

30. Ahsan S, Bhatti IA, Asi MR, Bhatti HN and MA Sheikh Occurrence of Aflatoxins in Maize Grains from Central Areas of Punjab, Pakistan. Int. J. Agric. Biol. 2010; 12(4): 571-575.

31. Ramesh J, Sarathchandra G and V Sureshkumar Survey of Market Samples of Food Grains and Grain Flour for Aflatoxin B1 Contamination. Int. J. Curr. Microbiol. Appl. Sci. 2013; 2(5): 184-188.

32. Matumba L, Monjerezi M, Khonga EB and DD Lakudzala Aflatoxins in Sorghum, Sorghum Malt and Traditional Opaque Beer in Southern Malawi. Food Control 2011; 22(2): 266-268.

33. Leroy JL, Wang J-S and K Jones Serum Aflatoxin B1-Lysine Adduct Level in Adult Women from Eastern Province in Kenya Depends on Household SocioEconomic Status: A Cross Sectional Study. Soc. Sci. Med. 2015; 146: 104-110.

34. Gitu KW Agricultural Development and Food Security in Kenya: Building a Case for More Support - The Case of Kenya. Working Paper No. 3. FAO, Rome, 2006. 


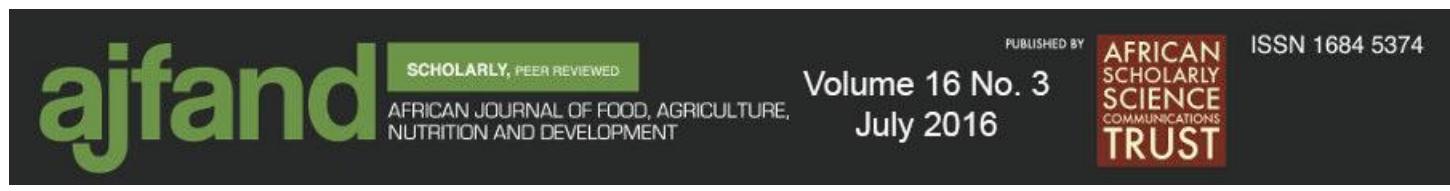

35. Muriuki GK and GM Siboe Maize Flour Contaminated with Toxigenic Fungi and Mycotoxins in Kenya. Afr. J. Health Sci. 1995; 2(1): 236-241.

36. Kimani-Murage EW, Madise NJ, Fotso J-C, Kyobutungi C, Mutua MK, Gitau TM, and $\mathbf{N}$ Yatich Patterns and Determinants of Breastfeeding and Complementary Feeding Practices in Urban Informal Settlements, Nairobi Kenya. BMC Public Health 2011; 11(1): 396.

37. Cullen JM, Ruebner BH, Hsieh LS, Hyde DM and DP Hsieh Carcinogenicity of Dietary Aflatoxin M1 in Male Fischer rats Compared to Aflatoxin B1. Cancer Res. 1987; 47(7): 1913-1917.

38. Mahdavi R, Nikniaz L, Arefhosseini SR and M Vahed Jabbari Determination of Aflatoxin M1 in Breast Milk Samples in Tabriz-Iran. Matern. Child Health J. 2010; 14(1): 141-145.

39. Sadeghi N, Oveisi MR, Jannat B, Hajimahmoodi M, Bonyani H and F Jannat Incidence of Aflatoxin M1 in Human Breast Milk in Tehran, Iran. Food Control 2009; 20(1): 75-78.

40. Wamani H, Åstrøm A, Peterson S, Tumwine JK and T Tylleskär Boys are More Stunted than Girls in Sub-Saharan Africa: A Meta-Analysis Of 16 Demographic And Health Surveys. BMC Pediatr. 2007; 7(1): 17.

41. Shephard GS Risk Assessment of Aflatoxins in Food in Africa. Food Addit. Contam. Part A 2008; 25(10): 1246-1256.

42. Coffey MT, Hagler WM and JM Cullen Influence of dietary Protein, Fat or Amino Acids on the Response of Weanling Swine to Aflatoxin B1. J. Anim. Sci. 1989; 67(2): 465-472.

43. Cotty PJ and R Jaime-Garcia Influences of Climate on Aflatoxin Producing Fungi and Aflatoxin Contamination. Int. J. Food Microbiol. 2007; 119(1-2): $109-115$.

44. Hell K, Cardwell KF, Setamou M and H-M Poehling The Influence of Storage Practices on Aflatoxin Contamination in Maize in Four Agroecological Zones of Benin, West Africa. J. Stored Prod. Res. 2000; 36(4): 365-382. 